\title{
A era digital na Antropologia Forense
}

\author{
A digital age in Forensic Anthropology \\ Una era digital en Antropología Forense
}

\section{Resumo}

Introdução: a produção de dados 3D tem-se revelado uma ferramenta útil na investigação e aplicação nas Ciências Forenses, contudo os avanços tecnológicos nem sempre são acompanhados pela legislação e comités de ética. Objectivo: aprofundar o tema do ponto de vista da Antropologia Forense. Metodologia: revisão bibliográfica sumária e consulta ao sistema jurídico português. Resultados: observa-se um vazio legislativo e uma ausência de normas éticas sobre a produção de dados 3D. Conclusão: é essencial que a revolução tecnológica seja acompanhada por um sistema jurídico adequado e comissões de ética estruturadas para uma evolução sustentável da Ciência.

Palavras-chave: Antropologia Forense. Ciência de dados. Sistema de justiça. Ética.

\begin{abstract}
Introduction: the 3D data production has proven to be a useful tool for Forensic Sciences, however technological advances are not always accompanied by updates of the Legislation and Ethics Committees. Objective: to develop the discussion on the subject from the point of view of Forensic Anthropology. Methodology: a summary review of the literature and consultation of the Portuguese legal system. Results: it is observable a legislative void and an absence of ethical norms about the 3D data production. Conclusion: it is essential that the technological revolution is followed by an adequate legal system and structured ethics committees for a sustainable evolution of Science.
\end{abstract}

Keywords: Forensic Anthropology. Data science. Justice administration system. Ethics.

\section{Resumen}

Introducción: la producción de datos 3D ha demostrado ser una herramienta útil en la investigación y aplicación en Ciencias Forenses, sin embargo, los avances tecnológicos no siempre van acompañados de Comités de Legislación y Ética. Objetivo: profundizar el tema desde el punto de vista de la Antropología Forense. Metodología: revisión bibliográfica resumida y consulta del sistema legal portugués. Resultados: hay un vacío legislativo y una ausencia de estándares éticos con respecto a la producción de datos 3D. Conclusión: es esencial que la revolución tecnológica vaya acompañada de un sistema legal adecuado y comisiones de ética estructuradas para una evolución sostenible de la Ciencia.

Palabras clave: Antropología Forense. Ciencia de los datos. Sistema de justicia. Ética.

\footnotetext{
1 Doutoranda em Antropologia Forense, financiamento pela FCT com referência de bolsa SFRH/BD/129826/2017, Universidade de Coimbra, Portugal; membro do Center for Functional Ecology (UID/BIA/04004/2019). http://orcid.org/00000001-7338-4955. E-mail: coelho.catarina.rs@gmail.com
} 


\section{Introdução}

A Antropologia Forense é um dos ramos das ciências forenses utilizado ao serviço da justiça. O contributo dessa área assume grande importância, tendo como principais objetivos a identificação de desconhecidos; auxiliar o patologista na determinação da causa e da circunstância da morte; e proceder à estimativa do tempo decorrido desde a morte (1).

Quando a identificação de um indivíduo está comprometida, geralmente pelo avançado estado de decomposição do cadáver, o antropólogo forense pode, através da análise do esqueleto, construir o perfil biológico e procurar fatores de individualização que permitam chegar a uma identificação positiva (2).

O contributo da Antropologia Forense tem reflexos no âmbito legal com as inerentes consequências jurídicas, como por exemplo, efeitos sucessórios, adoção de crianças órfãs ou a investigação de homicídios, que só pode ter início após emissão de um certificado de óbito subscrito pelo patologista, conforme artigo $14 .^{\circ}$ da Lei n. ${ }^{\circ}$ 45/2004, de 19 de Agosto (3), e após a identificação dos restos humanos $(4,5)$. A identificação de restos humanos é um ato de extrema importância e que se encontra consagrada no artigo $26 .^{\circ}$ da Constituição da República Portuguesa: "1. A todos são reconhecidos os direitos à identidade pessoal [...]" (6), e uma das características da identidade pessoal é o seu nome, que se encontra também descrito como direito no artigo $72^{\circ}$ do Código Civil Português (7).

É de referir que, segundo o 68.a artigo do Código Civil (7), após a morte cessa a personalidade jurídica (8). Contudo, no 71. o artigo do Código Civil pode ler-se:“Os direitos de personalidade gozam igualmente de proteção depois da morte do respetivo titular." (7), dessa forma, entende-se que mesmo após a morte existe um estatuto especial para o defunto (8) e, portanto, a sua identificação é essencial. No que respeita a questões éticas e humanitárias, os familiares e amigos também necessitam que o seu ente querido seja identificado para que possam realizar as cerimónias fúnebres e iniciar o luto (5).

Após a identificação dos restos cadavéricos desconhecidos, o antropólogo forense pode auxiliar o patologista, na estimativa do tempo decorrido desde a morte, também conhecido por intervalo post mortem. Uma estimativa correta do intervalo post mortem auxilia na interpretação dos eventos que ocorreram em torno da morte e coadjuva a determinar a pertinência forense dos restos humanos encontrados (9). De acordo com o Código Penal Português (10), o procedimento criminal extingue-se, por efeito de prescrição, logo que tiverem decorrido 15 anos sobre a prática do crime, quando se trata de crimes puníveis com 
pena de prisão cujo limite máximo for superior a 10 anos, como é o caso de homicídio, conforme os artigos $118^{\circ}$ e $131 .^{\circ}$ do Código Penal da redação dada pela Lei n. ${ }^{\circ} 44 / 2018$, de 9 de agosto. Portanto, de acordo com a lei portuguesa, um caso só tem enquadramento forense se a morte ocorreu até há 15 anos.

A investigação no âmbito da Antropologia Forense é essencial. O famoso caso Daubert v. Merrell Dow Pharmaceuticals, de 1993, é determinante no que diz respeito à produção de prova pericial (11). Esse caso reporta-se a uma ação apresentada por uma mulher que, durante as suas duas gravidezes, ingeriu medicamentos para o enjoo produzidos pela Merrel Dow e os seus dois filhos apresentavam deformidades congénitas. Segundo o perito contratado pela farmacêutica Merrel Down, o medicamento em causa não estava na origem dessas deformidades. Contudo, a farmacêutica Daubert apresentou um estudo não publicado sobre a administração desse mesmo fármaco a ratos cujas crias apresentaram deformidades (11). Após esse mediático caso, o Supremo Tribunal dos EUA decretou que todos os métodos empregues numa perícia forense têm de ser testados, avaliados pelos pares e publicados em revistas científicas (11). Ademais, o erro associado ao método tem de ser quantificável, o registo do método tem de ser padronizado e o método tem de ser aceite pela comunidade científica (11). Ora, ainda que no caso português os peritos não possam ser contratados pelas partes e, portanto, apresentam-se como uma autoridade pública isenta no processo judicial (12), contudo, as recomendações do Supremo Tribunal dos EUA são seguidas na aplicação dos métodos por parte da Antropologia Forense (1). Dessa forma, é essencial haver coleções osteológicas modernas para o desenvolvimento de métodos e também para testar os já desenvolvidos com objetivo de avaliar a precisão e reprodutibilidade dos mesmos (13).

Em Portugal existe, entre outras coleções identificadas, a Coleção de Esqueletos Identificados Século XXI (CEI/XXI), que se encontra no Laboratório de Antropologia Forense da Universidade de Coimbra. Essa coleção foi resultado de protocolo realizado entre o cemitério dos Capuchos em Santarém e o antigo Departamento de Antropologia, atualmente denominado Departamento de Ciências da Vida da Universidade de Coimbra, celebrado em 2009. Esse protocolo prevê a doação dos esqueletos de indivíduos que não fossem objeto de reclamação por parte das respetivas famílias após a exumação (14). 
Nos termos do regime jurídico da remoção, transporte, inumação, exumação, trasladação e cremação de cadáveres, conforme Decreto-Lei (DL) n. 411/98, de 30 de dezembro de 1998, na redação dada pela Lei n. 14/2016, de 09/06 (15):

Decorridos três anos após a inumação de um cadáver em sepultura temporária, ou quando findaram os processos de decomposição, procede-se à exumação do esqueleto. (15)

Após a exumação, as ossadas podem ser transladadas para um ossário, ou podem ser cremadas. Para esse efeito, os familiares são notificados sobre a data da exumação, podendo estar presentes ou não, tendo, no entanto, que informar o cemitério sobre qual é o final a dar aos restos ósseos. Caso os familiares não se pronunciem sobre o destino a dar aos restos esqueléticos, serão considerados abandonados e passam a ser responsabilidade do cemitério. A celebração do protocolo entre o Cemitério dos Capuchos em Santarém e a Universidade de Coimbra traduziu-se numa solução vantajosa, quer em termos autárquicos, no que a gestão espacial diz respeito, mas sobretudo no desenvolvimento da investigação em Antropologia Forense.

A CEI/XXI é composta por indivíduos adultos que morreram maioritariamente neste século, onde a idade, a morte, a data da inumação e o sexo são conhecidos, sendo uma coleção que reflete o perfil de mortalidade atual da população portuguesa (14) e que tem um enorme potencial no âmbito da Antropologia Forense.

Em Portugal, além dessa coleção osteológica existem também as Coleções Osteológicas Identificadas da Universidade de Coimbra e a Coleção Luís Lopes, em Lisboa, tal como a coleção de Esqueletos Identificados de Évora, que são coleções de referência usadas pela Antropologia Biológica e Paleopatologia. Essa tradição de criação de coleções de esqueletos identificadas é muito antiga, existindo coleções osteológicas em todo o mundo, como é possível verificar ao consultar o mapa criado pela Forensic Anthropology Society of Europe ${ }^{2}$ sobre as diferentes localizações de coleções osteológicas.

O objetivo deste artigo é aprofundar o assunto do ponto de vista da Antropologia Forense, através de uma revisão bibliográfica sumária e da consulta ao sistema jurídico português.

Tendo em consideração que os avanços tecnológicos podem ser utilizados em prol da justiça, é necessário que sejam alvo de escrutínio pelo sistema legislativo e ético, o que,

\footnotetext{
2 http://forensicanthropology.eu/osteological-collections/
} 
regra geral, não acompanha os avanços das técnicas. Para auxiliar nessa reflexão, no que concerne à Antropologia Forense, far-se-á uma revisão bibliográfica dos avanços tecnológicos do saber nessa área e na produção de dados 3D, procurando o possível enquadramento legal e ético no sistema judicial português.

\section{A imagiologia na Antropologia Forense}

A imagiologia aplicada às ciências forenses tem sido uma área de investigação que está em desenvolvimento acelerado. As técnicas de radiologia e imagiologia forense têm-se mostrado replicáveis, precisas e uma mais valia como fonte de informação no caso da investigação de mortes em contexto médico-legal (16). As imagens radiológicas também têm sido muito importantes na estimativa de alguns dos parâmetros do perfil biológico, no reconhecimento dos fatores individualizantes, que são de extrema importância na identificação, e também no auxílio da estimativa da idade em indivíduos vivos (16). Além disso, os métodos desenvolvidos para ser aplicados ao osso começam também a ser testados para avaliar se poderão ser utilizados em imagens, existindo já estudos que validaram alguns desses métodos (17).

A Antropologia virtual tem vindo a permitir não só a validação de métodos, mas também a possibilidade de se desenvolverem estudos longitudinais com pessoas vivas. No entanto, para que tal ocorra, é necessário a verificação de todos os procedimentos legais na realização da investigação, nomeadamente a solicitação de parecer a comissões de ética, conforme DL n. 80/2018 (18). Esse diploma tem por objetivo a "salvaguarda dos padrões de ética no âmbito das ciências da vida, por forma a proteger e garantir a dignidade e integridade humanas" em estudos com indivíduos vivos. Esses estudos são muito importantes, uma vez que as condições de saúde e nutrição melhoraram, tendo um consequente impacto no desenvolvimento esquelético (19). Eles permitem monitorizar, de forma não invasiva, as alterações que ocorrem a nível ósseo e melhorar os métodos já desenvolvidos, como, a título de exemplo, os usados na estimativa da idade à morte (17).

Outro grande marco do progresso dos métodos imagiológicos, aliados à medicina forense, é a utilização da virtópsia como método de auxílio na identificação da causa e da circunstância da morte $(20,21)$. A virtópsia - também conhecida por necrópsia virtual , um termo corrente no Brasil - permite a análise ao hábito interno do indivíduo de forma não invasiva, o que, em cenários como desastres de massa ou crenças religiosas contrárias à 
abertura do corpo, pode ser uma mais-valia, encontrando-se um equilíbrio entre a aplicação da lei e o respeito pela orientação religiosa em causa (20).

No caso português, de acordo com o Regime Jurídico das Perícias Médico Legais e Forenses - Lei n. ${ }^{\circ 45 / 2004}$, de 19 de agosto - o artigo 18. (3) enquadra as situações nas quais são realizadas as autópsias médico-legais. Assim:

1. A autópsia médico-legal tem lugar em situações de morte violenta ou de causa ignorada, salvo se existirem informações clínicas suficientes que associadas aos demais elementos permitam concluir, com segurança, pela inexistência de suspeita de crime, admitindo-se, neste caso, a possibilidade de dispensa de autópsia.

2. Tal dispensa nunca se poderá verificar em situações de morte violenta atribuível a acidente de trabalho ou acidente de viação dos quais tenha resultado a morte imediata. (3)

Nalguns grupos religiosos, como é o caso dos judeus e muçulmanos, colocam-se algumas das questões associadas à realização da autópsia, como se verá adiante. Contudo, a determinação judicial sobrepõe-se sempre às crenças e vontade da família. Com a virtópsia, essas questões sensíveis podem facilmente ser ultrapassadas (20). No contexto português, esses grupos não têm uma expressão significativa, mas em todo o mundo ocorrem situações em que a família e a sociedade se opõem à realização da autópsia, com a justificação de que sujeitará o corpo do(a) falecido(a) à profanação (20). A relutância da permissão dessa prática está intimamente relacionada com as crenças religiosas e os rituais fúnebres associados. A utilização do termo profanação de cadáver não pode ser equiparado ao que se encontra estabelecido no DL ํㅡ 48/95, artigo 254ํ do Código Penal (10), que considera a profanação de cadáver ou de lugar fúnebre:

1 - Quem:

a) Sem autorização de quem de direito, subtrair, destruir ou ocultar cadáver ou parte dele, ou cinzas de pessoa falecida;

b) Profanar cadáver ou parte dele, ou cinzas de pessoa falecida, praticando actos ofensivos do respeito devido aos mortos; ou

c) Profanar lugar onde repousa pessoa falecida ou monumento aí erigido em sua memória, praticando actos ofensivos do respeito devido aos mortos;

é punido com pena de prisão até 2 anos ou com pena de multa até 240 dias. 2 - A tentativa é punível. (10)

\section{As coleções digitais}

Nas últimas duas décadas, o desenvolvimento de métodos de visualização e análise de peças ósseas através de técnicas de imagiologia transformou o estudo dos organismos 
(22). Na Antropologia, a aplicação de técnicas imagiológicas, designadamente raio-X e a tomografia computorizada (TC), o laser, a luz estruturada, e a fotogrametria, revolucionaram o estudo da morfologia dos espécimes (22). Essas novas abordagens aumentaram exponencialmente o acesso a informação detalhada.

A UNESCO definiu "a digitalização é a criação de um objeto digital, análogo a um original através de um scanner, máquina fotográfica ou um equipamento elétrico." (23)

A tomografia computadorizada utiliza o raio- $X$, localizado numa ampola que se desloca ao longo do organismo e permite a obtenção de dados computorizados tridimensionais, sendo dessa forma possível avaliar secções ou cortes de áreas específicas do corpo (21). A vantagem em comparação à radiografia convencional é a possibilidade de ter uma imagem com volume e criar um modelo 3D dessas imagens. A sua grande desvantagem são os perigos das radiações ionizantes (21), mas que não se aplicam no caso de aquisição de imagens em esqueletos. A aplicação dessa técnica imagiológica a um crânio, por exemplo, apresenta vantagens no que diz respeito aos dados que se conseguem obter. Se a estrutura óssea estiver bem preservada e completa não é possível observar as estruturas internas da mesma, mas com recurso TC é possível ter acesso às estruturas internas e criar até modelos 3D dos mesmos (22).

Os equipamentos de luz estruturada, fotogrametria e laser permitem igualmente a criação de modelos 3D, mas não é possível aceder às estruturas internas como no caso da TC.

A criação de modelos 3D permitiu o desenvolvimento de novas técnicas de análise através da geometria morfométrica, que podem ser mais informativas do que os métodos clássicos (24). As investigações que decorrem em modelos 3D permitem concluir que essa abordagem é promissora na avaliação do esqueleto humano, uma vez que as análises realizadas envolvem decisões menos subjetivas e mais precisas, o que é fulcral no contexto da Antropologia Forense à luz das regras de Daubert $(24,25)$.

Com o aparecimento dos modelos 3D, outras vantagens podem ser elencadas, como a manutenção da preservação do material e o aumento e facilidade da partilha de informação na comunidade científica.

A digitalização de ossos humanos permite que as investigações ocorram sem a necessidade de interação com o material. Na perspetiva dos curadores de coleções osteológicas, é uma grande vantagem, uma vez que todas as investigações que decorrem 
com uma coleção contribuem para a degradação da mesma, pondo em causa a preservação da coleção osteológica $(22,23)$.

Outra das grandes vantagens é a partilha dos modelos 3D entre investigadores, tornando a investigação mais económica e rápida, uma vez que não seria necessário deslocar-se ao local onde se encontra a coleção $(22,23)$. Contudo, a partilha dos dados recolhidos pelos investigadores não se está a verificar (22).

As novas políticas de Ciência Aberta são cada vez mais uma constante na agenda da investigação científica. A maioria dos financiadores de projetos têm implementado, quer a nível internacional ou mesmo nacional - e no caso português a Fundação para a Ciência e Tecnologia -, normas sobre partilha dos dados (26). A regulamentação sobre a partilha varia entre a disponibilização dos dados em repositórios institucionais ou disponibilizados nos museus ou universidades, onde os dados foram recolhidos; as partilhas condicionadas sob solicitação dos dados aos investigadores que os recolheram; ou mesmo a não existência de qualquer obrigatoriedade da partilha de dados (26). Contudo, a ausência de normalização de partilha de dados mostra como essa questão ainda não se encontra bem resolvida (22).

Os investigadores contestam essa política por não ser clara e porque, muitas vezes, os dados publicados fazem parte de investigação de maiores dimensões que não se encontra terminada (22). Outra questão de elevada pertinência refere-se aos direitos de autor sobre aquisição de dados. Por exemplo, um investigador propõe-se a digitalizar uma coleção osteológica e é-lhe conferida a autorização, mas após o estudo, os modelos 3D têm de ser entregues segundo as regras da coleção. Outras investigações podem-se realizar com esses mesmos modelos cuja aquisição foi feita pelo primeiro investigador, mas não existe qualquer regulamentação sobre a autoria das digitalizações.

Analisando o Código do Direito de Autor e dos Direitos Conexos, DL n.ำ 100/2017, de 23/08 (27), os modelos 3D mesmo não estando enunciados podem ser enquadrados no $1^{\circ}$ artigo:

1 - Consideram-se obras as criações intelectuais do domínio literário, científico e artístico, por qualquer modo exteriorizadas, que, como tais, são protegidas nos termos deste Código, incluindo-se nessa proteção os direitos dos respetivos autores. (27)

No Artigo 13.ำ pode ler-se:

Aquele que subsidie ou financie por qualquer forma, total ou parcialmente, a preparação, conclusão, divulgação ou publicação de uma obra não adquire 
por esse facto sobre esta, salvo convenção escrita em contrário, qualquer dos poderes incluídos no direito de autor." Segundo este artigo, os dados só podem ser considerados pertença da instituição quando existe uma convenção escrita, mesmo nos projetos financiados por agências de investimento para a investigação. (27)

No Artigo 14. deste mesmo código é possível ler-se:

2 - Na falta de convenção, presume-se que a titularidade do direito de autor relativo a obra feita por conta de outrem pertence ao seu criador intelectual. (27)

Pode-se usar a mesma analogia para os autores que fazem a aquisição dos modelos.

A disponibilização dos dados encontra-se protegida pelo artigo 35.ㄹ, sobre obra publicada ou divulgada em partes (27):

1 - Se as diferentes partes, volumes ou episódios de uma obra não forem publicados ou divulgados simultaneamente, os prazos de proteção legal contam-se separadamente para cada parte, volume ou episódio.

Esse parece o artigo mais pertinente para enquadrar a partilha de dados, que só deve ser obrigatória após toda a investigação se encontrar concluída.

A questão dos direitos de autor ainda não reúne consenso entre investigadores, curadores de coleções, instituições de ensino público e agências de financiamento de investigação (22). É expectável que, quando houver uma regulamentação uniforme sobre a partilha de dados, se irá perceber o verdadeiro potencial dos modelos 3D na era de dados abertos.

Os modelos 3D não se encerram nessa problemática, após a aquisição e tratamento das imagens 3D é possível fazer a impressão dos modelos com equipamentos adequados, que cada vez mais estão atingíveis porque os seus custos têm vindo a diminuir substancialmente. Posto isto, um modelo que detém informações muito detalhadas pode ser analisado e manuseado tal como o espécime que lhe deu origem.

\section{A impressão de modelos 3D e a ética}

A integração de modelos 3D no ensino da anatomia e osteologia tem-se mostrado uma ótima forma de aplicação dessa tecnologia. Sendo cada vez mais um cenário possível encontrar nas aulas de anatomia partes de cadáveres ou peças ósseas que são réplicas 3D. Contudo, é essencial encontrar o enquadramento legal das réplicas, uma vez que há autores que defendem que os "modelos 3D podem ser definidos como os dados que representam 
restos humanos em formato digital" (23). Sendo os modelos 3D reproduções do cadáver, não Ihe podem ser equiparados para a aplicação do artigo 20. do DL n. $\stackrel{0}{274 / 99}$, de 22 de julho (28):

Quem, para os fins previstos no artigo 1.․․ comercializar cadáver ou partes dele, ou peças, tecidos ou órgãos, é punido com pena de prisão de 2 a 10 anos.

Contudo, a reprodução de modelos 3D e a sua comercialização podem ter aplicação análoga ao artigo 199. do DL $n$. ⒋/95, de 15 de março (10), no que se refere às gravações e fotografias ilícitas. Há dois tipos de crime: a recolha de imagens de forma ilícita e a sua divulgação. Segundo o acordo de 29 de maio de 2012 do Tribunal da Relação, o direito à imagem:

Trata-se de um bem jurídico eminentemente pessoal com a estrutura de uma liberdade fundamental e que reconhece à pessoa o domínio exclusivo sobre a sua própria imagem. (29)

E sendo as réplicas 3D tão precisas, deve-se prevenir a questão da identificação através dos traços fisiológicos. Uma vez que essas técnicas têm alta precisão pode-se entrar em incumprimento com artigo 8. do DL $\mathrm{n} . .^{\circ} 274 / 99$, de 22 de julho, que regula a dissecação de cadáveres (28):

4 - Os dados podem ser utilizados para fins de ensino, elaboração de trabalhos de investigação científica e recolha de dados estatísticos, desde que não sejam identificáveis as pessoas a que respeitam.

Prevê-se um claro benefício da utilização de réplicas de cadáveres ou partes do mesmo em escolas médicas onde não existam programas de doadores de cadáveres, uma vez que podem ter acesso a esse tipo de recursos para o ensino (30). Podendo essa nova abordagem ser a resposta para:

[...] a carência de material humano para fins de ensino e investigação constitui uma realidade preocupante cuja dimensão tem aumentado drasticamente ao longo das últimas décadas, com substanciais e inevitáveis reflexos negativos no progresso das ciências da saúde e na formação dos profissionais desta área.

A dissecação de cadáveres e a sua utilização para fins de ensino e de investigação científica assume efetivamente um papel essencial e insubstituível na didática das ciências da saúde, revestindo-se de incontestável importância no âmbito da formação geral e especializada dos profissionais da saúde e na evolução do conhecimento nesta área do saber. Tal prática, ao possibilitar um melhor conhecimento do organismo humano, a 
compreensão dos fenómenos patológicos e o aperfeiçoamento de métodos de diagnóstico e terapêutica, habilitará melhor o profissional a cuidar dos vivos, configurando-se como garantia da qualidade dos atos médicos e cirúrgicos e do seu aperfeiçoamento contínuo. Permitirá, ainda, que no estudante se desenvolva um processo educativo no âmbito de valores, de atitudes e de comportamentos essenciais para que o futuro profissional da saúde assuma na plenitude a sua missão, contribuindo em última análise para a promoção do bem-estar dos indivíduos e da sociedade em geral. (28).

No artigo $3 .^{\circ}$ do DL $n .^{\circ} 274 / 99$, de 22 de julho (28), encontram-se identificados os atos permitidos, no que diz respeito à utilização de cadáveres:

1 - É permitida a realização dos atos previstos no artigo $1 .^{\circ}$ quando a pessoa falecida tenha expressamente declarado em vida a vontade de que o seu cadáver seja utilizado para fins de ensino e de investigação científica. Esta declaração de vontade é revogável, a todo o tempo, pelo próprio.

2 - Fora dos casos previstos no número anterior, é permitida a dissecação de cadáveres ou de partes deles, para os fins previstos no artigo 1.․․ desde que:

a) A pessoa não tenha manifestado em vida, junto do Ministério da Saúde, a sua oposição; e

b) A entrega do corpo não seja, por qualquer forma, reclamada no prazo de vinte e quatro horas, após a tomada de conhecimento do óbito, pelas pessoas referidas no artigo $4 . \stackrel{\circ}{\circ}$, n. -1 .

3 - É, ainda, permitida a extração de peças, tecidos ou órgãos, para os fins

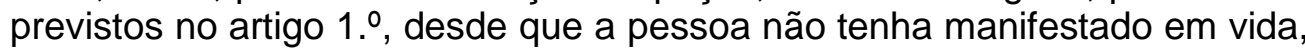
junto do Ministério da Saúde, a sua oposição. (28)

Percebe-se que mesmo que não exista uma declaração em vida da vontade da pessoa, o seu cadáver pode ser usado para fins de ensino e de investigação científica. Numa era em que as bases de dados são um enorme potencial de investigação, variados estudos podem ser feitos. Atualmente, podem ser criados não só os espécimes anatómicos, os tecidos ou órgãos são alvo de investigação, mas também os modelos 3D, que podem ser adquiridos a partir dos cadáveres, e as bases de dados para mapear e avaliar diferentes variáveis do corpo humano, como foi explanado anteriormente. A combinação de uma investigação científica que tem uma sede desmedida de dados com uma lei bastante vasta sobre a utilização de cadáver para ensino e investigação (30) podem levantar questões de diversas naturezas.

Analisando em particular os casos em que as pessoas em vida realizam os procedimentos necessários para que o seu corpo seja objeto de investigação, um dos passos é o preenchimento da declaração de doação do corpo à ciência. Essa declaração não apresenta qualquer tipo de informação sobre os dados que podem ser recolhidos, quais as investigações que poderão ser feitas, ou que é possível recriar, em modelos 3D, partes ou 
um corpo completo. Considerando que é uma das atitudes mais altruístas que o ser humano pode ter, todos deviam poder escolher quais os estudos em que queriam participar, devendo existir um consentimento informado, algo semelhante ao que acontece nos estudos com pessoas vivas. Por outras palavras, devia estar disponível informação detalhada sobre os estudos que podem ser realizados com o corpo humano e cada pessoa deveria poder escolher em que tipo de estudos gostaria que o seu corpo participasse. É verdade que os estudos realizados só são feitos após a morte do indivíduo, contudo o indivíduo tem, em vida, a preocupação que o seu corpo seja útil na evolução da investigação científica.

\section{Conclusão}

A Antropologia Forense é uma das ciências forenses que serve a justiça. Para melhor responder às questões de especial importância, necessita testar as metodologias existentes e desenvolver novas para se adequarem aos padrões de variação populacional atuais. Uma das formas de fazer investigação é em coleções osteológicas identificadas, outra é através da análise de dados produzidos pelas técnicas imagiológicas.

A imagiologia tem revolucionado várias áreas das ciências forenses, uma vez que em alguns casos é possível até encontrar equilíbrio entre a aplicação da justiça e as ideologias religiosas, como é o caso da virtópsia. Como em Portugal "a autópsia-médico legal é obrigatória nos casos previstos na lei" (31), a virtópsia pode, em minorias religiosas, ser a solução para ultrapassar constrangimentos.

Outra revolução tecnológica é a criação de modelos 3D, a sua utilização e impressão. Sendo os modelos 3D uma revolução na conceção da observação de dados, ainda muito se tem de escrever e legislar sobre o assunto. Até ao momento, não existem normas sobre a utilização desses modelos como recurso no ensino da Antropologia (32) nem, como se viu no supra exposto, relativamente à réplica de cadáveres ou de partes dos mesmos. Indo ao encontro de Samelo (8) que, em 2015, defendeu que "mesmo após a morte existe um estatuto especial para o defunto", muito há ainda que refletir sobre os modelos 3D e as suas implicações éticas e morais na sociedade.

Não se pretende com este artigo dar soluções legislativas ou éticas sobre os avanços tecnológicos, apenas se pretende apresentar algumas considerações da parte da Antropologia Forense, mostrando aquilo que parece ser vazios legais e éticos decorrentes 
desses avanços científicos, e sugerindo ser essencial unir forças entre as ciências e o Direito para uma profunda reflexão sobre o assunto.

\section{Referências}

1. Cunha E. Considerações sobre a Antropologia Forense na actualidade. Revista Brasileira de Odontologia Legal. 2017, 4(2): 110-117. Disponível em http://portalabol.com.br/rbol/index.php/RBOL/article/view/133. [Acesso em 20 jun.2019]

2. Cunha E, Cattaneo C. Historical Routes and Current Practice for Personal Identification. In: Ferrara SD, organizador. P5 Medicine and Justice. Cham: Springer International Publishing AG; 2017. p. 399-411.

3. Portugal. Lei n. 45/2004, de 19 de agosto de 2004 regime jurídico das perícias médicolegais e forenses. Diário da República Série I-A. Disponível em:

https://data.dre.pt/eli/lei/45/2004/08/19/p/dre/pt/html; [Acesso em 2.jul.2019].

4. Caplova Z, Obertova Z, Gibelli DM, De Angelis D. Mazzarelli D, Sforza C, Cattaneo C. Personal Identification of Deceased Persons: An Overview of the Current Methods Based on Physical Appearance. Journal of Forensic Sciences. (3 out 2017), 63 (3):662-671. DOI: 10.1111/1556-4029.13643

5. Christensen AM, Anderson BE. Methods of Personal Identification. In: Langley NR; Tersigni-Tarrant MA, organizadores. Forensic Anthropology a comprehensive introduction. segunda edição. Florida, CRC Press; 2017. p.163-174.

6. Portugal. Constituição da República Portuguesa. Diário da República n. 86/1976, Série I de 1976-04-10. Disponível em: https://dre.pt/web/guest/legislacao-consolidada//lc/337/201908090557/127985/diploma/indice; [Acesso em 5.jul.2019]

7. Portugal. Código Civil. Diário do Governo n.ำ274/1966, Série I de 1966-11-25. Disponível em: https://dre.pt/legislacao-consolidada/-/lc/34509075/view; [Acesso em 3.jul.2019].

8. Samelo NTCR. Aspectos relativos à tutela post-mortem da personalidade humana no direito civil. [Dissertação]. Coimbra: Mestrado na área de especialização em Ciências Jurídico-Forenses, Universidade de Coimbra; 2015.

9. Ferreira MT, Cunha E. Can we infer post mortem interval on the basis of decomposition rate? A case from a Portuguese cemetery. Forensic Science International. (10 mar 2013), 226 :298.e1-298.e6. DOI: http://dx.doi.org/10.1016/j.forsciint.2013.01.006

10. Portugal. Código Penal. Diário da República n.ำ63/1995, Série I-A de 1995-03-15. Disponível em: https://dre.pt/web/guest/legislacao-consolidada/-/lc/34437675/view; [Acesso em 4.jul.2019]. 
11. Lesciotto KM. The Impact of Daubert on the Admissibility of Forensic Anthropology Expert Testimony. Journal of Forensic Sciences. (26 fev 2015), 60 (3):549-555. DOI: $10.1111 / 1556-4029$

12. Lourenço MJ. Prova pericial científica: análise comparada dos regimes jurídicos de Portugal e dos EUA. Scientia Luridica - Tomo LXVII, 2018, 348 :347-368.

13. Austin D, King R. The Biological Profile of Unidentified Human Remains in a Forensic Context. Academic Forensic Pathology. (1 set 2016), 6 (3):370-390. DOI: https://doi.org/10.23907/2016.039

14. Ferreira MT, Vicente R, Navega D, Gonçalves D, Curate F, Cunha E. A new forensic collection housed at the University of Coimbra, Portugal. The 21st century identified skeletal collection. Forensic Science International. (6 out 2014), 245 :202.e1-202.e5. DOI: http://dx.doi.org/10.1016/j.forsciint.2014.09.021

15. Portugal. Decreto-Lei n. ${ }^{0} 411 / 98$, de 30 de dezembro de 1998. Inumação e trasladação de cadáveres. Disponível em:

http://www.pgdlisboa.pt/leis/lei_mostra_articulado.php?nid=246\&tabela=leis\&so_miolo=; Acesso em [10.jul.2019].

16. Aaldersa MC, Adolphic NL, Dalyd B, Davise GG, de Boerf HH, Deckerg SJ, Dempersh JJ, Fordg J, Gerrardc CY, Hatchc GM, Hofmani PAM, Linoj M, Jacobsenk C, Kleinl WM, Kubatm B, Lethn PM, Mazuchowskio EL, Noltec KB, O'Donnellp C, Thaliq MJ, van Rijnb $\mathrm{RR}$, Wozniaks K. Research in forensic radiology and imaging; Identifying the most importante issues. Journal of Forensic Radiology and Imaging. (20 jan 2017), 8:1-8. DOI: http://dx.doi.org/10.1016/j.jofri.2017.01.004

17. Dedouit F, Martin PS, Mokrane FZ, Savall F, Rousseau H, Crubézy E, Rougé D, Telmon N. Virtual anthropology: useful radiological tools for age assessment in clinical forensic medicine and thanatology. Radiology Medicine. (5 mar 2015), 120 :874-886. DOI 10.1007/s11547-015-0525-1.

18. Portugal. Decreto-Lei $n . .80 / 2018$, de 15 de outubro de 2018. Estabelece os princípios e regras aplicáveis às comissões de ética que funcionam nas instituições de saúde, nas instituições de ensino superior e em centros de investigação biomédica que desenvolvam investigação clínica. Disponível em: https://dre.pt/home/-/dre/116673880/details/maximized; [Acesso em 10.jul.2019].

19. Edgar HJH. Biohistorical approaches to "race" in the United States: Biological Distances Among African Americans, European Americans, and Their Ancestors. American Journal of Physical Anthropology. (18 fev 2009), 139 :58-67. DOI: 10.1002/ajpa.20961

20. Andrade SLMD. Virtópsia: O adeus ao bistori?. [Dissertação]. Coimbra. Ciclo de estudos de mestrado integrado em medicina, Universidade de Coimbra; 2015. Disponível em: https://estudogeral.sib.uc.pt/handle/10316/30482. [Acesso em 1.mai.2019]. 
21. Franklin D, Swift L, Flavel A. 'Virtual anthropology' and radiographic imaging in the Forensic Medical Sciences. Egyptian Journal of Forensic Sciences. (8 jun 2016), 6:31-43. DOI: http://dx.doi.org/10.1016/j.ejfs.2016.05.011

22. Davies TG, Rahman IA, Lautenschlager S, Cunningham JA, Asher RJ, Barrett PM, Bates KT, Bengtson S, Benson RBJ, Boyer DM, Braga J, Bright JA, Claessens LPAM, Cox PG, Dong X, Evans AR, Falkingham PL, Friedman M, Garwood RJ, Goswami A, Hutchinson JR, Jeffery NS, Johanson Z, Lebrun R, Donoghue PCJ, et al. Open data and digital morphology. Proceedings Royal Society B. (12 abr 2017), 284: 1-10. DOI: http://dx.doi.org/10.1098/rspb.2017.0194

23. Hassett BR. Which Bone to Pick: Creation, Curation, and Dissemination of Online 3D Digital Bioarchaeological Data. Journal of the World Archaeological Congress. (04 jul 2018), 14 (2):231-249. DOI: https://doi.org/10.1007/s11759-018-9344-z

24. Slice D. Modern morphometrics in physical anthropology. London: Kluwer Academic/Plenum; 2005.

25. Dias P, Neves L, Santos D, Coelho C, Ferreira MT, Santos H, Silva S, Santos B. S. CraMs: Craniometric Analysis Application Using 3D Skull Models. IEEE Computer Graphics and Applications. (18 nov 2015), 35 (6):11-17. DOI 10.1109/MCG.2015.136

26. Hahnel Mark. Global funders who require data archiving as a condition of grants. Figshare, 2015. Disponível em:

https://figshare.com/articles/Global_funders_who_require_data_archiving_as_a_condition_ of_grants/1281141 [Acesso em 14.jul.2019].

27. Portugal. Código do Direito de Autores e dos Direitos Conexos. Diário da República n.ำ 61/1985, Série I de 1985-03-14. Disponível em: https://dre.pt/web/guest/legislacaoconsolidada/-/lc/34475475/view; [Acesso em 14.jul. 2019].

28. Portugal. Decreto-Lei n. ${ }^{\circ}$ 274/99, de 22 de julho de 1999. Regula a dissecação de cadáveres e extração de peças, tecidos ou órgão para fins de ensino e de investigação científica. Diário da República n. 169/1999, Série I-A de 1999-07-22. Disponível em: https://data.dre.pt/eli/dec-lei/274/1999/07/22/p/dre/pt/html, [Acesso em 13.jul.2019].

29. Portugal. Acórdão do Tribunal da Relação de Évora, de 29/05/2012. Processo n.ำ 253/07.3 JASTB.E1. Relator: Martinho Cardoso. Disponível em:

http://www.dgsi.pt/jtre.nsf/134973db04f39bf2802579bf005f080b/341f5e5d5b6f39f580257de $10056 \mathrm{f} 84 \mathrm{c}$ ?

30. Cornwall J. The ethics of 3D-printing copies of bodies donated for medical education and research: What is there to worry about?. Australasian Medical Journal. (31 jan 2016), 9 (1):8-11. DOI: http://dx.doi.org/10.4066/AMJ.2015.2567

31. Pereira AGD. O Consentimento (Informado) na Actividade Pericial Forense. Revista Portuguesa do Dano Corporal, 2005, $15: 11-45$. 
32. L'Abbé E. Bioethics in Bakeng se Africa, the use of human remains in research and teaching, Pretoria, 2019. Disponível em: https://bakengsa.wixsite.com/skeleton [Acesso em 02.jul.2019].

Como citar este artigo:

Coelho C. A era digital na Antropologia Forense. Cadernos Ibero-Americanos de Direito Sanitário. 2020 jan./mar.; 9(1): 141-156.

http://dx.doi.org/10.17566/ciads.v9i1.594 